\title{
Role of Perceived Career \\ Development Opportunities in Predicting Employee Commitment and Subjective Career Satisfaction of Middle Managers in Commercial Banks in Sri Lanka
}

\author{
Wickramaratne, W.P.R. ${ }^{1{ }^{*}}$ \\ ${ }^{1}$ Department of Human Resource Management, University of Peradeniya, Peradeniya, 20400, Sri Lanka.
}

Received: 23 November, 2020, Revised: 31 December, 2020, Accepted: 28 January, 2021.

How to Cite this Article: Wickramaratne, W.P.R. (2021). Role of perceived career development opportunities in predicting employee commitment and subjective career satisfaction of middle managers in commercial banks in Sri Lanka. Sri Lanka Journal of Social Sciences and Humanities, 1(1), 23-32.

\begin{abstract}
In today's dynamic and uncertain employment climate, both employers and employees must play an active role in the development of employee careers. This research fills a gap in the existing literature by evaluating the role of organizational career development opportunities in predicting subjective career satisfaction and commitment of employees in a developing country context. Understanding the impact of career development opportunities provided by the employer and their effects on subjective career satisfaction and commitment is important to both the organization and the individual in the current uncertain and unpredictable employment climate. Data were collected, via an online survey, from 224 middle managers of commercial banks in Sri Lanka, and evaluated using multiple hierarchical regression analysis. The findings, which have important implications for policymakers, indicate that the employee's perception of the provision of career development opportunities by the organization promotes them to develop their subjective career satisfaction and commitment. These outcomes provide implications to the extended model of social cognitive career theory and Meyer and Allen's model of commitment. In terms of policy implications, the organizations should create a supportive career development culture to build a belief in employees that the organization they work for cares about their career needs. This belief can be built by considering individual employees' personal career goals in the implementation of career development programs and informing employees about available career development opportunities within the organization. The limitations of the study and the directions for future research are also discussed.
\end{abstract}

Keywords: Career development opportunities, Subjective career satisfaction, Affective commitment, Normative commitment, Sri Lanka

\section{INTRODUCTION}

In today's world of global connectedness and the dynamic, social, economic, and technological changes, the role of career development programs such as career counselling services is very crucial for both employers and employees (Kononiuka et al., 2020; Peila-Shuster et al., 2019). The contemporary concept of career is different from the traditional concept, in that the responsibility for managing careers has shifted from the employer to the employee and to a greater focus on career self-management (Arthur et al., 2005; De Vos et al., 2009; Stickland, 1996; Sullivan, 1999). Despite the growing importance of career self-management, organizational career management remains an integral responsibility of firms, since it forms the context in which career development takes place (Baruch, 1999; Eby, Allen, \& Brinley, 2005).

Despite the declining importance of organizational career development in the current context, the extant literature reports some empirical gaps in the relationship between organizational career development opportunities and employee commitment and career satisfaction outcomes. Most of the studies report that the employee perceptions of or- ganizational career development opportunities lead to career satisfaction (Allen, Eby, Poteet, Lentz, \& Lima, 2004; Barnett \& Bradley, 2007; Guan et al., 2015; Price \& Reichert, 2017). However, Ng et al. (2005), in their meta-analysis, claimed that there is mixed evidence regarding the amount of variance in career satisfaction explained by organizational career development opportunities. This variability could be partly explained by the lack of empirical research that uniquely predicts subjective career satisfaction (Ng et al., 2005). In line with commitment related theories, Bambacas (2010, p. 821) suggests that "given the changing organizational circumstances in managing careers, there is a need for continued research into career management practices that elicit components of organizational commitment to the organization." More specifically, normative commitment is a little researched area in this relationship (Bambacas, 2010). As most of the prior studies in these areas have been conducted in developed countries, these findings may not be representative of other parts of the world. For example, some country-specific studies have found that there are dif- 
ferences between countries in terms of attitudes and behaviours (Chen \& Francesco, 2000; Kickul et al., 2004; Yu \& Egri, 2005) there is a necessity of implementing culturally sensitive career development practices (Storlie et al., 2016). Therefore, there is a necessity to conduct country-specific studies in the area of career development. While national culture is not explicitly treated as a relevant factor in this study, the fact that it is one of the very few studies of the relationship between organisational career development opportunities and commitment that was conducted in developing countries makes it significant in testing the generalizability of previous results (Kumar \& Krishnaveni, 2008; Paul \& Anantharam, 2004). More studies are likely needed in other regions to verify if these findings can be generalized to other countries.

\section{RESEARCH OBJECTIVES}

Based on the afore discussed gaps in the extant literature, the overarching problem of this study was to determine whether the organizational career development opportunities offered by organizations have a positive effect on employee level outcomes of commitment and subjective career satisfaction. The study established three specific objectives as given below to address the overarching problem of the study.

1. To study the effect of organizational career development opportunities on affective commitment.

2. To find out the impact of organizational career development opportunities on normative commitment.

3. To examine the role of organizational career development opportunities on subjective career satisfaction.

The study made four main significant contributions. First, the western findings were verified by conducting the study in a developing country context. Second, the study addressed the claim of prior studies about the necessity of conducting more studies in this area of study (e.g., Bambacas, 2010; Bambacas and Bordia, 2009). Third, the findings provided implications to the policymakers and $\mathrm{HR}$ practitioners. Finally, the study provided implications to the theories and models such as the extended model of social cognitive career theory (Lent and Brown, 2006) and the commitment model of Meyer and Allen (1997).

\section{LITERATURE REVIEW}

\section{Role of Organizational Support in Influencing Employee Outcomes}

In order to better understand the relationship between perceived career development opportunities and the employee outcomes of commitment and career satisfaction, the tenets of the extended model of social cognitive career theory of Lent and Brown (2006) and the proactive behaviour model as applied to the career domain (Crant, 2000) were consulted. These models unpack how organizational career development opportunities and employee outcomes of career satisfaction and commitment are related. The extended model of social cognitive career theory (Lent \& Brown, 2006) proposes that people are more likely to take actions to achieve their goals if they have access to environmental (organizational) support and resources relevant to the pursuit of these goals. The extended model of social cognitive career theory (Lent \& Brown, 2006) suggests that the organizational career development opportunities belong to a class of environmental support and resource variables that are specifically relevant to the pursuit of an individual's career goals. Therefore, organizational career development opportunities provide social and material support for one's personal goals are likely to be significant predictors of employee outcomes such as career satisfaction (Barnett \& Bradley, 2007; Lent \& Brown, 2006, Ng et al; 2005) and employee commitment (Bashir \& Ramay, 2008; Crant, 2000; Paul \& Ananntharaman, 2004).

\section{Organizational Career Development Opportunities (OCDO) and Commitment}

As suggested by the theory of proactive behaviour (Crant, 2000), contextual/environmental support such as organizational career development opportunities, positively affects job attitudes such as employee commitment. Moreover, research suggests that the receipt of organizational support for career development will contribute to the fulfillment of the psychological contract between employer and employee. Consequently, as a means of reciprocation, the employees feel committed to the organization (Sturges et al., 2005). In line with the prediction of the theory of proactive behaviour, together with Meyer and Allen's (1997) model of commitment and social exchange theory (Blau, 1964), HRM practices, including those that focus on career development, are the most frequently examined predictors of organizational commitment (Paul \& Ananntharaman, 2004). The literature suggests that career development enhances employee career opportunities within the organization and ultimately contributes to employee commitment (Paul \& Ananntharaman, 2004). More importantly, employee career development opportunities that are managed by the organization are important factors in the management literature, since they have a strong relationship to positive organizational outcomes such as commitment. OCDO has been shown to result in higher levels of commitment among employees (Bashir \& Ramay, 2008; Paul \& Ananntharaman, 2004).

Prior studies have found that the employee perceptions of OCDO are positively related to affective attachment to the organization (Bambacas, 2010; Bambacas \& Bordia, 2009; De Vos et al., Jongseok, Youngbae, \& Tae-Yeol, 2009; Kumar \& Krishnaveni, 2008; Paul \& Ananntharaman, 2004; Sturges et al., 2005; Sturges, Guest, Conway, \& Davey, 2002). For example, Sturges et al. (2005) collected data through a survey of 151 employees of a new media company in the UK and revealed that informal career development help, such as being given career advice when needed, is positively associated with the affective commitment of employees. In a previous longitudinal study of 212 graduates - in the first ten years of their career - sampled from five large UK organizations, Sturges et al. (2002) found that the career management help is given to employees through formal interventions, such as training, orientations, and personal development plans are positively related to their affective commitment. However, this study did not find a significant relationship between informal help for career development (impartial career advice and introduction by the organization to people who might help with career development) and affective commitment.

Bambacas and Bordia (2009) surveyed 196 managers who were members of a professional association of general managers, the Australian Institute of Management, in South Australia. Organizational career development was measured by the type of assistance organizations offered individuals in their career development, and investigated career development practices, such as the provision of challenging assign- 
ments, career counselling, and support for career development. This study found that these career development opportunities were positively associated with affective commitment. The other studies mentioned above have also used similar types of "assistance" to operationalise the OCDO, whereas the affective commitment was measured with the affective commitment scale of Meyer and Allen (1991). These studies were based on a diverse set of organizations: large corporations, auto component manufacturing firms, and software companies.

Previous research also suggests that individuals tend to feel an obligation to stay with the organization (normative commitment) when they are provided with career development opportunities (Bambacas, 2010; Kumar \& Krishnaveni, 2008; Meyer \& Allen, 1997). Bambacas (2010) measured organizational career development opportunities in terms of career development assistance such as work assignments, career counselling, and being provided with information about the organization and the industry. Kumar and Krishnaveni (2008) found that career planning is positively associated with the normative commitment of employees. Meyer and Allen (1997) based on a review of literature, claimed that HRM practices such as career management are positively associated with normative commitment. The theoretical predictions and empirical findings discussed in this section led to establish the following hypotheses.

Hypothesis 1: Organizational career development opportunities have positive effects on affective commitment.

Hypothesis 2: Organizational career development opportunities have positive effects on normative commitment.

\section{Organizational Career Development Opportunities and Subjective Career Satisfaction}

Career satisfaction measures the extent to which individuals believe their career progress is consistent with their own goals, values, and performances (Erdogan et al., 2004; Heslin, 2003; Ng et al., 2005; Seibert \& Kraimer, 2001). Career satisfaction is often measured using the career satisfaction scale developed by Greenhaus et al. (1990). The vast majority of studies measuring career satisfaction have used this scale (e.g. Arthur et al., 2005; Aryee \& Chang, 1994; Barnett \& Bradley, 2007).

In relation to the direct link between $O C D O$ and career satisfaction, as predicted by the extended model of social cognitive career theory (Lent \& Brown, 2006) and the theory of proactive behaviour (Crant, 1983), career literature provides evidence for a positive relationship between OCDO and the career satisfaction of employees (Allen, Eby, Poteet, Lentz, \& Lima, 2004; Barnett \& Bradley, 2007; Guan et al., 2015; Guan et al., 2014; Lent \& Brown, 2006; Ng et al., 2005; Orpen, 1994; Pazy, 1988).

Orpen (1994) surveyed 129 employees working in a variety of organizations in the UK, in both the private and public sectors. This study was based on the supervisory and middle managerial positions and found that the career development policies and practices (feedback, provision of information, career plans, and job rotation) are jointly related to career satisfaction. This study developed a 35 item career development questionnaire based on a workshop conducted with 10 randomly selected personnel managers. Pazy (1988) operationalized organizational career development in terms of formal career policies and procedures in the organization (selection, admission, assessment, promotion, training, and development), and found that these policies and procedures together impact career satisfaction.
This finding is related to a survey conducted based on the employees of a variety of US organizations.

Lent and Brown (2006), based on a review of literature relating to work satisfaction in a vocational and educational setting, suggest that goal-specific environmental supports and resources, such as social and material support, promote work satisfaction. This study operationally defined career satisfaction as overall feeling about one's job.

Based on a survey of 90 private and public sector employees in Australia, Barnett and Bradley (2007) found that there is a positive relationship between different kinds of organizational career development help, formal interventions such as career training, orientation, and being given a personal development plan as well as informal help provided by the organization, such as impartial career advice and introduction to people who might help with career development and employees' subjective career satisfaction. That is, goal-specific environmental support and resources that provide social and material provision for employees' personal goals have been identified as major predictors of career satisfaction (Barnett \& Bradley, 2007). Barnett and Bradley (2007) measured OCDO by using the scale of organizational support for career development developed by Sturges et al. (2002). Therefore, the organizational support for the career development of this study includes the programs, processes, and assistance provided by the organizations to support and enhance their employees' career success. The career satisfaction was measured with the subjective career satisfaction scale of Greenhaus et al. (1990). Two recent surveys of employees in China, (Guan et al., 2014; Guan et al., 2015) also have found that the OCDOs are positively related to the career satisfaction of employees.

Furthermore, support for a positive relationship between OCDO and career satisfaction was found in two meta-analyses (Allen et al., 2004; Ng et al., 2005). Allen et al. (2004) found that individuals who participated in career mentoring were more satisfied with their careers than non-mentored individuals. Similarly, $\mathrm{Ng}$ et al. (2005) revealed that career development opportunities are positively associated with the career satisfaction of employees. Career development in this study refers to career planning, career sponsorship (career assistance received from senior employees), supervisor support, training and skill development, and organizational resources.

In addition to these studies, the career literature provides evidence for a positive relationship between individual career development practices and subjective career satisfaction (Arthur et al., 2005; Aryee \& Chay, 1994). Based on a review of the literature, Arthur et al. (2005) found that there is a positive relationship between mentoring, or social support, and subjective career satisfaction. Aryee and Chay (1994) administered a structured survey to 164 professional and managerial employees in a range of private and public sector organizations in Singapore. This study found that organizational career development opportunities, in terms of career-oriented mentoring (coaching, sponsorship, protection, challenging assignments, and exposure), were positively associated with subjective career satisfaction of employees. Several observations are made about these studies. First, $\mathrm{Ng}$ et al. (2005), in their meta-analysis, claimed that there is mixed evidence regarding the amount of variance in career satisfaction explained by OCDO. This variability could be partly explained by the lack of empirical research that uniquely predicts subjective career satisfaction ( $\mathrm{Ng}$ et al., 
2005). This may be due to the confounding of objective career success and subjective career success. Career success is defined as the accumulated positive work and psychological outcomes resulting from one's work experiences (Seibert \& Kraimer, 2001). Researchers often operationalize career success in one of two ways. The first includes variables that measure objective or extrinsic career success (e.g., Gutteridge, 1973). These include indicators of career success that can be seen and therefore evaluated objectively by others, such as salary attainment and the number of promotions in one's career (Judge et al., 1995). The second way that career success is operationalized is by variables that measure subjective or intrinsic career success (e.g., Judge et al., 1995). Such variables capture individuals' subjective judgments about their career attainments, such as job and career satisfaction (e.g., Burke, 2007; Judge et al., 1999). Job satisfaction has been defined as "a pleasurable or positive emotional state resulting from an appraisal of one's job or job experiences" (Loke, 1976, p.1300). Conversely, career satisfaction is derived from an individual's appraisal of his/her career development and advancement across many jobs (Greenhaus, Parasuraman, \&Wormley, 1990). For example, Joo and Park (2010) defined career satisfaction as an indicator of subjective career success and further measured career satisfaction by using a scale developed by Greenhaus, Parasuraman, and Wormley (1990). Some of the items included in this scale are: "I am satisfied with the progress I have made towards meeting my goals for income" and "I am satisfied with the progress I have made for advancement" (Greenhaus et al., 1990). The vast majority of career studies have also used the Greenhaus et al. (1990) scale for measuring subjective career satisfaction (e.g. Arthur et al., 2005; Aryee \& Chang, 1994; Barnett \& Bradley, 2007). Numerous studies have operationally defined subjective career success either as job satisfaction or career satisfaction (Erdogan et al., 2004; Heslin, 2003; Ngo, Lau, \& Foley, 2008; Seibert \& Kraimer, 2001). In a review of 49 career success studies, Arthur et al. (2005) identified 20 studies that included measures of career satisfaction, while 11 studies included measures of job satisfaction to measure subjective career success. Heslin (2005) argued that job satisfaction does not cover satisfaction over a longer period, including a wide range of outcomes, such as sense of purpose and work-life balance, and is therefore not an appropriate proxy for career success.

Career satisfaction is commonly considered to be the subjective version of career success, defining individuals' satisfaction with their career accomplishments (Judge, Cable, Boudreau, \& Bretz, 1995). When career satisfaction has been operationalised, it measures the extent to which employees believe that their career progress is in agreement with their own goals, values, and preferences (Erdogan et al., 2004). These limitations can be dealt with by defining and measuring objective career success by using supplementary measures of subjective career success (Barnett \& Bradley, 2007).

Gattiker and Larwood (1988) argued that traditional career studies are focused on objective measures of career success, i.e. outcomes of the work experience such as status, promotion, and salary, all of which are objectively observable. Some objective career success measures are not relevant today because of constraints imposed by firms in providing these opportunities (Heslin, 2005). Measures of subjective career satisfaction may be a more appropriate indicator of career outcomes in the contemporary environment. The change in focus, from objective career satisfaction to subjective career satisfaction, is that career satisfaction is internal rather than external in the new career context of career selfmanagement (Hall \& Chandler, 2005).

Second, most of the studies to date have been conducted in developed countries such as the USA, UK, Australia, and Singapore. As discussed previously, there are differences between countries in terms of attitudes and behaviours, limiting the generalizability of prior literature outcomes to other country contexts.

Overall, this theoretical discussion indicates that "subjective career satisfaction" is the most suited dimension for subjective career success. A lack of studies in developing economies, mixed results about the amount of variance in the relationship between OCDO and career satisfaction, and limited studies of the relationship between OCDO and subjective career satisfaction were the research gaps in the extant literature. Based on the prediction of the extended model of the social cognitive career theory and the prior empirical findings, the following hypothesis was established.

Hypothesis 3: Organizational career development opportunities have a positive effect on subjective career satisfaction. Based on the literature reviewed in this section the hypothetical relationships were established between the variables, and the following conceptual framework was presented which guided the study. According to the conceptual framework, the variable 'organizational career development opportunities' is the predictor variable whereas affective commitment, normative commitment, and subjective career satisfaction are the outcome variables.

\section{Figure 1: Conceptual Framework}

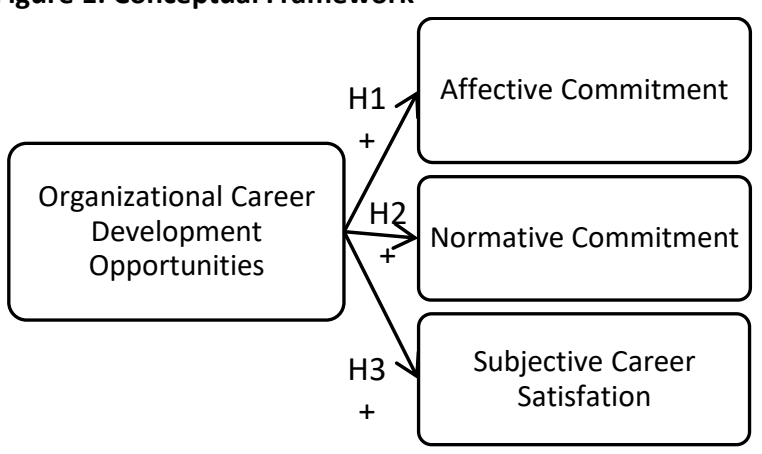

\section{METHOD}

\section{Sample and data collection procedure}

The current study was based on the middle-level managers of licensed commercial banks in Sri Lanka. Commercial banks in Sri Lanka were selected given that the financial sector is an important contributor to Sri Lanka's economy contributing 9.6\% to the Gross Domestic Product and $1.9 \%$ to national employment (Central Bank of Sri Lanka, Annual Report, 2019). The sampling frame of this study refers to all of the middle-level managers in licensed commercial banks. 300 surveys were distributed among middle managers in local banks whereas 100 surveys were distributed among middle managers in foreign banks. Out of 400 surveys, only 224 completed surveys were returned.

All the survey measures were chosen from prior research based on their established validity and prior application within the area of career development. Measurement scales relating to affective commitment and normative commitment were measured with a seven-point scale with 7 , representing strongly agree and 1 , representing strongly disagree. 
All other scales used a five-point scale where 5 , represented strongly agree and 1 , represented strongly disagree.

\section{Operationalization of Variables}

This section provides operational definitions and measurement information for the variables in the study.

Perceived organizational career development opportunities. Employee perceptions of career development opportunities were defined as the opportunities that organizations provide to advance an individual employee's career prospects within the organization (King, 2003). Employees were asked about the extent to which they have experienced different kinds of organizational career development opportunities available within the organization. The dimensions of career development opportunities included career-oriented training, provision of a personal development plan, supervisor feedback, and support from other employees (Sturges et al., 2002). A scale previously used and validated by Sturges et al. (2002) was used to measure the employee perceptions of organizational career development opportunities and included items such as "I have received training to help develop my career" and "I have been given a personal development plan". This scale includes dimensions such as

Career satisfaction. Career satisfaction was operationally defined as the extent to which individuals believe that their career progression is consistent with their own goals, values, and preferences (Erdogan et al., 2004; Heslin, 2003; Seibert $\&$ Kraimer, 2001). The dimensions of subjective career satisfaction included satisfaction with own success, satisfaction with achieved career goals, satisfaction with income, and the satisfaction with new skills developed (Greenhaus et al., 1990). Most of the prior studies have used the career satisfaction scale developed and validated by Greenhaus et al. (1990) to measure career satisfaction $(\infty=.88)$. This scale was used in this study. The scale included items such as: "I am satisfied with the success I have achieved in my career," and "I am satisfied with the progress I have made towards meeting my overall career goals."

Affective commitment and normative commitment. Meyer and Allen's (1997) definitions for affective and normative commitment were adhered to in this study. An affective commitment was measured in terms of willingness to stay with the firm because of emotional attachment to it and identification with it as well as involvement in the organization, whereas normative commitment was measured in terms of the employees' feeling of a moral obligation to stay with the organization. Thus, 'the extent of emotional attachment to the organization' was the dimension of affective commitment whereas 'the extent of moral obligation to stay with the current employee' was the dimension of normative commitment (Meyer \& Allen, 1997). Many career studies to date (e.g., Joo \& Park, 2010; Maurer \& Lippstreu, 2008; Sturges et al, 2002) have utilized the affective commitment scale developed by Meyer, Allen, and Smith (1993). Consistent with prior research, this study adopted Meyer et al. (1993) six-item questionnaire to measure affective commitment $(\infty=.86)$; it included items such as: "I would be very happy to spend the rest of my career life with this organization." and "this organization has a great deal of personal meaning for me".

Similarly, prior studies (e.g. Bambacas, 2010; Bambacas\& Bordia, 2009) have measured normative commitment with the six-item normative commitment scale $(\infty=89)$ developed by Meyer et al., (1993). The current study has adopted this scale to measure normative commitment; it included items such as: "I would feel guilty if I left my organization now." and "I would not leave my organisation right now because I have a sense of obligation to the people in it."

\section{DATA ANALYSIS PROCEDURE}

The first step of the data analysis was a confirmatory factor analysis to verify whether the survey responses fall into the pre-determined factor structure. This step was followed since the study employed questionnaires developed and validated by the other researchers. The second step of the data analysis involved a hierarchical regression analysis to test the hypotheses of the study. Hierarchical regression analysis allowed controlling the effects of demographic variables on the proposed relationships between variables.

\section{RESULTS AND DISCUSSION}

\section{Demographics of Respondents}

After dealing with missing data, 224 responses out of 408 surveys distributed were retained for the analysis, which resulted in a $56 \%$ response rate. The demographic profile of respondents, such as age and tenure, are presented in Table 1. Out of the 224 responses retained for the analysis, 167 employees $(76 \%)$ were male who represented middle management level employees.

Table 1: Respondents Age and Employment Period

\begin{tabular}{|c|c|c|c|}
\hline \multicolumn{2}{|c|}{ Age } & \multicolumn{2}{|c|}{ Employment Period } \\
\hline Years & Percentage of Employees & Years & Percentage of Employees \\
\hline $18-25$ & 3.2 & $<1$ & 2.7 \\
\hline $26-33$ & 38.0 & $1-5$ & 23.8 \\
\hline $34-41$ & 33.5 & $6-10$ & 30.2 \\
\hline $42-49$ & 14.9 & $11-15$ & 21.2 \\
\hline $50-55$ & 8.4 & $16-20$ & 12.2 \\
\hline $55<$ & 2.0 & $21<$ & 9.9 \\
\hline
\end{tabular}

Source: Survey data, 2020.

\section{Results of the Factor Analysis}

As the conceptual structure of the study was derived from work in prior studies and utilised previously validated measurement scales, the study used the confirmatory factor analysis (CFA). The purpose of CFA was to test whether the collected data fit with the hypothesized measurement model. The following measures which were proposed by Hair et al.,
(2018) were used to interpret the correlation matrix relating to the factor analysis.

$>\quad$ Visual inspection of correlations in the component correlation matrix shows that the factors are interrelated to some degree. The fact that these correlations exist tells us that the constructs measured are interrelated. 
Bartlett's test of sphericity was used to test the presence of correlations among variables. A statistically significant Bartlett's test of sphericity (sig.<.05) indicates that sufficient correlations exist among variables. The overall measure of sampling adequacy (MSA) for the set of variables included in the analysis was 0.869 , which exceeds the minimum requirement of 0.50 for overall MSA. The probability associated with Bartlett's Test of Sphericity was $<0.001$ which was less than 0.05 . Therefore, the overall measure of sampling adequacy is acceptable.

Using a CFA with oblique rotation (Costello \& Osborne, 2005; Hair et al., 2018; Tabachnick \& Fidell, 2013), four factors with Eigenvalues greater than 1 were identified. The cumulative proportion of variance criteria met with eight components to satisfy the criterion of explaining $60 \%$ or more of the total variance. A four components solution explained $65.37 \%$ of the total variance.

The communality value for each variable was higher than 0.50 . Consequently, all of the items were retained in the analysis, since factor solutions represent a significant proportion of variance in the original variables. As suggested by Hair et al. (2018) all loadings above \pm .40 were considered as factor loadings with practical significance. The strong conceptual foundation for the anticipated structure and its rationale provided the basis for the interpretation of the factor structure (Hair et al., 2010). The factor solution is given in Table 2. The factors indicated in this table were named based on underlying conceptual dimensions and results from previous studies.



Source: Survey data, 2020.

\section{Correlations}

The mean values, standard deviations, correlations, and Cronbach's alpha coefficients are presented in Table 3. The mean age of respondents was 42.5 years and the average number of years individuals had been with their organization was eight. Values on the diagonal represent Cronbach's alpha coefficients, which are above the generally agreed upon lower limit of 0.80 . Therefore, each scale measures study variables with consistency. 
Table-3: Correlation Matrix of Variables

\begin{tabular}{|c|c|c|c|c|c|c|c|c|c|}
\hline & Mean & S.D. & 1 & 2 & 3 & 4 & 5 & 6 & \\
\hline 1. Age (Years) & 42.5 & 15.7 & & & & & & & \\
\hline 2. Gender & $\mathrm{N} / \mathrm{A}$ & NA & $-.198 * *$ & & & & & & \\
\hline 3. Tenure (Years) & 8 & 3.1 & $.587^{* *}$ & .051 & & & & & \\
\hline 4. OCDO & 3.71 & .68 & -.082 & .074 & .068 & .897 & & & \\
\hline 5. Affective Commitment & 3.6 & .74 & .129 & .120 & $.211 * *$ & $.357^{* *}$ & .835 & & \\
\hline 6. Normative Commitment & 3.64 & .82 & .104 & $.148^{*}$ & $.157^{*}$ & $.424 * *$ & $.603 * *$ & .857 & \\
\hline 7. Career Satisfaction & 3.86 & .64 & -.036 & -.021 & -.061 & $.403 * *$ & $.383 * *$ & $.452 * *$ & .878 \\
\hline
\end{tabular}

Source: Survey data, 2020.

\section{Testing Hypotheses}

Hypothesis 1 of the study predicts that employee perception of OCDO has a positive effect on affective commitment whereas Hypothesis 2 of the study predicts that the employee perception of OCDO has a positive effect on normative commitment. Table 4 shows that OCDO has a significant positive relationship with affective commitment $(\beta=.352$, $p$ $<.05)$ and normative commitment $(\beta=.429, p<.05)$ when the effects of the demographic variables were controlled in Step 1 of the hierarchical regression. In accordance with the $\mathrm{R}$ Square values, $16 \%$ of the variance of affective commitment, and $22 \%$ of the normative commitment is explained by the OCDO. Therefore, the first two hypotheses were supported by this study.

Hypothesis 3 of the study predicted that employee perceptions of OCDO have a positive effect on subjective career satisfaction. As shown in Table 3, there is a significant positive relationship between OCDO and subjective career satisfaction $(\beta=.386, p<.05) .19 .8 \%$ variance of subjective career satisfaction is explained by the OCDO (Adjusted R Square $=0.198$ ). Therefore, Hypothesis- 3 of the study is accepted.

Table 4: Hierarchical Regression Examining the Impact of OCDO on Affective Commitment, Normative Commitment and Subjective Career Satisfaction

\begin{tabular}{lcccccc}
\hline & \multicolumn{2}{c}{ Affective Commitment } & \multicolumn{2}{c}{ Affective Commitment } & \multicolumn{2}{c}{ Subjective Career Satisfaction } \\
$\begin{array}{l}\text { Predictors } \\
\text { (Beta Coefficients): }\end{array}$ & Step 1 & Step 2 & Step 1 & Step 2 & Step 1 & Step 2 \\
\hline Gender & & & & & & .013 \\
Tenure & $.211^{*}$ & $.187^{*}$ & $.169^{*}$ & $.134^{*}$ & -.021 & .061 \\
OCDO & & $.352^{*}$ & & $.429^{*}$ & & $.386^{*}$ \\
F & $10.217^{*}$ & $22.078^{*}$ & $5.355^{*}$ & $21.360^{*}$ & $3.731^{*}$ & $16.382^{*}$ \\
Adj. R-Square & .040 & .160 & .038 & .219 & .052 & .198 \\
R-Square change & & .120 & & .183 & & .145 \\
\hline Note: ${ }^{*}=$ p $<.05$ & &
\end{tabular}

Source: Source: Survey data, 2020.

As expected, the organization's provision of career development opportunities has a positive effect on both the employees' emotional attachment (affective commitment) to the organization and their feelings of obligation to the organization (normative commitment). The significant positive effect of OCDO on affective commitment found in this study supports prior literature (Bambacas, 2010; Bambacas \& Bordia, 2009; De Vos et al., Jongseok, Youngbae, \& Tae-Yeol, 2009; Kumar \& Krishnaveni, 2008; Paul \& Ananntharaman, 2004; Sturges et al., 2005; Sturges, Guest, Conway, \& Davey, 2002). This study also supports the previous literature, which suggests that individuals tend to feel an obligation to stay with the organization when they are provided with career development opportunities (Bambacas, 2010; Kumar and Krishnaveni, 2008; Meyer \& Allen, 1997). As expected, the organization's provision of career development opportunities has a positive effect on subjective career satisfaction. The finding here is that it enhances satisfaction in addition to creating commitment. The positive relationship between OCDO and subjective career satisfaction implies that the employees believe that their career progression is consistent with their own goals, values, and preferences as a result of receiving opportunities for their career development. This outcome of the study supports the prior literature (Allen, Eby, Poteet, Lentz, \& Lima, 2004; Barnett \& Bradley, 2007; Guan et al., 2015; Guan et al., 2014; Lent \& Brown, 2006; Ng et al., 2005; Orpen, 1994; Pazy, 1988). Two recent studies also support this research outcome (Guan et al., 2014; Guan et al., 2015). Furthermore, this outcome provides support for a positive relationship between OCDO and career satisfaction found in two meta-analyses (Allen et al., 2004; Ng et al., 2005). Also, the current study provides general support for a positive relationship between individual career development practices and subjective career satisfaction found in prior studies (Arthur et al., 2005; Aryee \& Chay, 1994). However, the current study contributes by addressing some deficiencies in extant literature. First, $\mathrm{Ng}$ et al. (2005), in their meta-analysis, claimed that there is mixed evidence regarding the amount of variance in career satisfaction explained by OCDO. This variability could partly be explained by the lack of empirical research that uniquely predicts subjective career satisfaction (Ng et al., 2005). In response to this gap, the current finding broadened the knowledge in this area of inquiry. Second, most of the studies to date have been conducted in developed countries such as the USA, UK, Australia, and Singapore. As discussed previously, there are differences between countries in terms of attitudes and behaviours, limiting the generalizability of prior literature outcomes to other country contexts. Though this deficiency was addressed, it was found that the finding is consistent with what was found in developed countries.

\section{Theoretical implications}


The results of the study provide implications to the extended model of social cognitive career theory (Lent \& Brown, 2006) and the theory of proactive behaviour (Crant, 2000). That is, referring to the extended model of social cognitive career theory (Lent \& Brown, 2006), organisational support for career development needs to be specifically relevant to an individual's career goals. Therefore, organisational career development opportunities, which provide social and material support for personal career goals, are likely to be significant predictors of career satisfaction (Barnett \& Bradley, 2007; Lent $\&$ Brown, 2006). As suggested by the theory of proactive behaviour (Crant, 2000), contextual/environmental support such as organisational career development opportunities, positively affects job attitudes such as employee commitment (Cicekli and Kabasakal, 2017). Moreover, the research outcomes suggest that the receipt of organisational support for career development will contribute to the fulfilment of the psychological contract between employer and employee binding both parties with some reciprocal obligations. Consequently, as a means of reciprocation, the employees feel committed to the organisation (Sturges et al., 2005).

\section{Policy implications}

The results of the study highlight the importance of building a supportive culture for employee career development. That is, in a career development culture, employees are expected to grow, are supported, and are rewarded for their success (Simonsen, 1997). One way of creating such a supportive career development culture is to build a belief in employees that the organization they work for cares about their career needs (Kraimer\& Wayne, 2004). This belief can be built by considering individual employees' personal career goals in the implementation of career development programs and informing employees about available career development opportunities within the organization (Sturges et al., 2005, Sturges et al., 2000). Moreover, just the provision of career development opportunities is not enough. The managers should convince employees that they take an interest in their employees' career development. For this, supervisors should always make sure that their employees get the right training, that employees get impartial career advice, and introduce employees to other organizational members who can assist with their careers (Sturges et al., 2005, Sturges et al., 2000)

On a policy level, budgetary allocations for networking and recognition events may be made by the organization. Also, many companies have moved to web-based training in the interest of increased cost-effectiveness. But this is a solitary process. Therefore, group training, particularly off-site, may cost more, but it provides networking opportunities, and may also be seen as recognition. These sorts of policy changes may be implemented via HR managers and through other managers. The managers who implement these policies should be rewarded for providing opportunities for their staff. Also, the employees would feel a reciprocal obligation (Rousseau, 1989) towards the organization because of receiving these types of support. That is, motivationally focused organizational actions such as career-oriented organizational support, will enhance employees' willingness to fully invest themselves physically, cognitively, and emotionally into their work roles (employee engagement) (Barrick et al., 2015). The outcome would be an emotional attachment to the organization, the feeling of an obligation to stay with the organization (Allen \& Meyer, 1997), and a belief that their career progression is consistent with their career goals and preferences (Barnett \& Bradley, 2007; Crant, 2000; Lent
\& Brown, 2006). Overall, policymakers can learn from the study that they should build reciprocal obligations in employees by considering employee career goals in making career decisions and by regularly informing employees of all available career development opportunities within the organization so that the employees will have reasons to believe that the organization cares about their career needs. The other way that the organization can build a supportive career culture is to provide actual career development opportunities and practices, such as career training, provision of personal career development plans, provision of performance feedback by supervisors, career advice, provision of work that enhances skills for the future, and mentoring (Sturges et al., 2005; Sturges et al., 2000).

\section{Study limitations and directions for future research}

Although this study has made some important contributions to the theory and practice of career development and career self-management, it has some minor limitations. The selected sample of employees consisted mainly of middle managers of commercial banks in Sri Lanka. These managers usually have more opportunities for career development, so their expectations may be quite different from employees at different levels in the organization. Therefore, there is a need to investigate employees at different levels of the organization and to see how the provision of career development opportunities, or lack thereof, influences their perceptions of commitment and career satisfaction. This limitation may affect the generalizability of the findings to other managerial and non-managerial levels within the same industry. The study addresses this limitation to a certain extent with a broad definition given for the middle manager. That is middle managers of this study consist of employment categories such as branch manager, assistant manager, manager, and sectional head.

Because of the time factor, the research was limited to a cross-sectional study, which means that it is not possible to conclude cause and effect among items based on employee responses. The research was also limited to a random sample of middle-level managers in commercial banks in Sri Lanka, and data were gathered only via a survey. Therefore, results are subject to common method bias and common source. However, to reduce this effect, the item ambiguity was minimized through minor modifications in the questionnaire. Moreover, prior research suggests that showing significant correlations in previous studies may enhance confidence in the study's results (Craig, Dunn, \& Hult, 2012). In line with this argument, the results of the current study show significant correlations between variables confirming the validity of the results. Furthermore, steps were taken to minimize or eliminate potential effects from self-report bias by collecting data independently of respondents' employers to reduce motives to respond favorably. That is, data were collected over the internet so that respondents could complete them in private and had control over their progress through the instruments (Richman et al., 1999).

The use of a career satisfaction scale to measure subjective career satisfaction may be another limitation of the study. While the standardized scale is used widely and obtains acceptable levels of internal consistency (Greenhaus et al., 1990), it may be a deficient measure of the subjective career satisfaction construct. The career satisfaction scale includes items, such as satisfaction with income and advancement goals, which may not be the most important criteria used by individuals to assess their career satisfaction (Heslin, 2005). 
Since this empirical model was tested in a developing country, future studies should investigate the same in different country contexts. In addition to the need for exploring these findings, in different country contexts, there should be continued research into the relationship between organizational career development opportunities and normative commitment, since limited studies have investigated this relationship. Also, future studies could be conducted with a greater representation of different levels of employees in an organizational hierarchy to improve the generalizability of findings to other contexts. In addition, to increase the generalizability, more studies in various industries representing diverse employee groups are needed. To avoid bias due to a common source, future studies should be conducted based on information from various sources, such as employees and their seniors and juniors. Moreover, a qualitative study is worthwhile to provide further support for the findings of this study. Affective commitment, normative commitment, and subjective career satisfaction are not the only employee outcomes affected by organizational career interventions and individual career self-management behaviours. Therefore, this study could be expanded by the inclusion of other outcome variables such as continuance commitment and subjective motivation. Future studies could also replace organizational commitment with career commitment since the literature provides indications of a direct relationship between career development and career commitment (Colarelli \& Bishop, 1990). "Career commitment means the strength of one's motivation to work in a chosen career role" (Hall, 1971, p.59). Chang (1999) found that career commitment mediates the relationship between employee perceptions of supervisor support and affective commitment. A further interesting area for future research is to incorporate cultural values, beliefs, and attitudes as antecedents of organizational career development, since cross-cultural studies have identified differences between cultures in behaviour and attitudes (Kickul et al., 2004; Yu \& Egri, 2005).

\section{CONCLUSION}

The results revealed that the organizational career development opportunities have a positive effect on employee outcomes of affective and normative commitment and career satisfaction. While addressing the theoretical gaps in the extant literature, this study is one of the first investigations conducted in a developing economy to find whether the organizational career development opportunities lead to enhanced employee commitment and career satisfaction. Thus, the current study makes significant contributions to the theory, identifies avenues for further research, and will be of interest to policymakers in management practice.

\section{REFERENCES}

Allen, T.D., Eby, L.T., Poteet, M.L., Lentz, E., \& Lima, L. (2004). Career benefits associated with mentoring for proteges: a meta-analysis. Journal of Applied Psychology, 89, 127-135.

Arthur, M. B., Khapova, S. N., \& Wilderom, C. P. M. (2005). Career Success in a boundaryless career world. Journal of Organizational Behavior, 26, 177-202.

Aryee, S., \& Chang, Y.W. (1994). An examination of the impact of careeroriented mentoring on work commitment, attitudes, and career satisfaction among professional and managerial employees. British Journal of Management, 5, 241-249.

Bambacas, M. (2010). Organizational handling of careers influences managers' organizational commitment. Journal of Management Development, 29(9), 807-827.

Bambacas, M., \& Bordia, P. (2009). Predicting different commitment components: the relative effects of how career development HRM practices are perceived. Journal of Management \& Organization, 15, 224-240.

Barnett, B.R., \& Bradley, L. (2007). The impact of organizational support for career development on career satisfaction. Career Development International, 12(7), 617-636.

Barrick, M. R., Thurgood, G. R., Smith, T. A., \& Courtright, S. H. (2015). Collective organizational engagement: Linking motivational antecedents, strategic implementation, and firm performance. Academy of Management Journal, 58(1), 111-135.

Baruch, Y. (1999). Integrated career systems for the 2000s. International Journal of Manpower, 20(7), 432-457.

Bashir, S., \& Ramay, M. I. (2008). Determinants of organizational commitment: a study of information technology professionals in Pakistan. Institute of Behavioral and Applied Management, 226-238.

Blau, P. (1964). Exchange and power in social life. New York: John Wiley.

Burke, L. A., \& Hutchins, H. M. (2007). Training transfer: An integrative literature review. Human Resource Development Review, 6, 263-296.

Central Bank of Sri Lanka. (2019). 2019 annual report. Colombo: Central Bank of Sri Lanka.

Chang, E. (1999). Career commitment as a complex moderator of organizational commitment and turnover intention. Human Relations, 52(10), 1257-1278.

Chen, Z.X., \& Francesco, A.M. (2000). Employee demography, organizational commitment, and turnover intentions in China: Do cultural differences matter? Human Relations, 53(6), 869-887.

Colarelli, S. M., \& Bishop, R. C. (1990). Functions, correlates, and management. Group and Organization Studies, 15(2), 158-176.

Craighead, C. A., Jr, D. J. K., Dunn, K. S., \& Hult, T. M. (2012). The impact of career mentoring and psychosocial mentoring and affective organizational commitment, job involvement and turnover intention. Administration and Society, 1-25.

Crant, J.M. (2000). Proactive behavior in organizations. Journal of Management 26(3), 435-462.

De Vos, A., Dewettinck, K., \& Buyens, D. (2009). The professional career on the right track: A study on the interaction between career selfmanagement and organizational career management in explaining employee outcomes. European Journal of Work and Organizational Psychology, 18(1), 55-80.

Eby, L. T., Allen, T. D., \& Brinley, A. (2005). A cross-level investigation of the relationship between career management practices and careerrelated attitudes. Group and Organization Management, 30(6), 565596.

Erdogan, B., Kraimer, M.L., \& Liden, R.C. (2004). Work value congruence and intrinsic career success: the compensatory roles of leader-member exchange and perceived organizational support. Personnel Psychology, 57(2), 305-332.

Greenhaus, J.H., Parashurama, S., \& Wormley, W. (1990). Effects of race on organizational experiences, job performance evaluations, and career outcomes. Academy of Management Journal, 33(1), 64-86.

Guan, Y., Jiang, P., Wang, Z., Mo, Z., \& Zhu, F. (2017). Self-referent and other-referent career successes, career satisfaction, and turnover intention among Chinese employees: The role of achievement motivation. Journal of Career Development, 44(5), 379-393.

Hair, J.F., Black, W.C., Babin, B.J., \& Anderson, R.L., (2018). Multivariate data analysis, 8th ed. New Jersey: Prentice-Hall.

Hall, D. T., \& Chandler, D. E. (2005). Psychological success: When the career is a calling. Journal of Organizational Behavior, 26(2), 155-176.

Heslin, P.A. (2003). Self- and other-referent criteria of career success. Journal of Career Assessment, 11(3), 262-286.

Heslin, P.A. (2005). Conceptualizing and evaluating career success. Journal of Organizational Behavior, 26(2), 113-136.

Joo, B.K., \& Park, S. (2010). Career satisfaction, organizational commitment, and turnover intention: The effects of goal orientation, organizational, learning culture and developmental feedback. Leadership \& Organization Development Journal, 31(6), 482-500.

Judge, T.A., Cable, D.M., Boudreau, J.W., \& Bretz, R.D. (1995). An empirical investigation of the predictors of executive career success. Personnel Psychology, 48(3), 485-519.

Kickul, J., Scott, W., \& Belgio, E. (2004). Attitudinal and behavioral outcomes of psychological contract breach: A cross-cultural comparison of the United States and Hong Kong Chinese. International Journal of Cross-Cultural Management, 4(2), 229-252. 
King, Z. (2003). New or traditional careers? A study of UK graduates' preferences. Human Resource Management Journal, 13(1), 5-26.

Kononiuka, A., Pająkb, A., Gudanowskaa, A. E., Magruka, A., Kozłowskaa, J., \& Sacio-Szymańskab, A. (2020). Foresight for career development. Форсайm, 14(2 (eng)).

Kraimer, M. L., \&Wayne, S. J. (2004). An examination of perceived organizational support as a multidimensional construct in the context of an expatriate assignment. Journal of Management, 30, 209-237.

Kumar, N.R., \& Krishnaveni, R. (2008). Role of HRD practices in building organizational commitment. Journal of Contemporary Research in Management, 59-68.

Lent, R.W., \& Brown, S.D. (2006). Integrating person and situation perspectives on work satisfaction: a social-cognitive view. Journal of Vocational Behavior, 69, 236-247.

Meyer, J., \& Allan, N.J. (1991). A three-component conceptualization of organizational commitment. Human Resource Management Review, 1(1), 61-89.

Meyer, J., \& Allen, N. (1997). Commitment in the workplace: Theory, research, and application. Thousand Oaks, CA: Sage.

Meyer, J.P., Stanley, D.J., Herscovitch, L., \& Topolnytsky, L. (2002). Affective, continuance, and normative commitment to the organization: A meta-analysis of antecedents, correlates, and consequences. Journal of Vocational Behavior, 61(1), 20-52.

Ng, T.W.H., Eby, L.T., Sorensen, K.L., \& Feldman, D.C. (2005). Predictors of objective and subjective career success: a meta-analysis. Personnel Psychology, 58, 367-408.

Ngo, H.Y., Lau, C., \& Foley, S. (2008). Strategic human resource management, firm performance, and employee relations climate in China. Human Resource Management, 47(1), 73-90.

Orpen, C. (1994). The effects of organizational and individual career management on career success. International Journal of Manpower 15(1), 27-37.

Paul, A.K., \& Ananntharaman, R.N. (2004). Influence of HRM practices on organizational commitment: A study among software professionals in India. Development Quarterly, 15(1), 77-88.

Pazy, A. (1988). Joint responsibility: The relationships between organizational and individual career management and the effectiveness of careers. Group and Organization Studies, 13(3), 311-331.

Peila-Shuster, J. J., Carlson, L. A., \& Huff, A. E. (2019). Children's career development: the building blocks for career adaptability. In Handbook of Innovative Career Counselling (pp. 231-249). Springer, Cham.

Price, S., \& Reichert, C. (2017). The importance of continuing professional development to career satisfaction and patient care: meeting the needs of novice to mid-to late-career nurses throughout their career span. Administrative Sciences, 7(2), 17.

Richman, W., Kiesler, S., Weisband, S., \& Drasgow, F. (1999). A metaanalytic study of social questionnaires, and interviews. Journal of $A p-$ plied Psychology, 84, 754-775.

Rousseau, D. M. (1989). Psychological and implied contracts in organizations Employee Responsibilities and Rights. Journal of Vocational Behavior, 2, 121-139.

Seibert, S.E., \& Kraimer, M.L. (2001). The five-factor model of personality and career success. Journal of Vocational Behavior, 58, 1-21.

Stickland, R. (1996). Career self-management-can we live without it? European Journal of Work and Organizational Psychology, 5, 583-596.

Storlie, C. A., Mostade, S. J., \& Duenyas, D. (2016). Cultural trailblazers: Exploring the career development of Latina first-generation college students. The Career Development Quarterly, 64(4), 304-317.

Sturges, J., Conway, N., Guest, D., \& Liefooghe, A. (2005). Managing the career deal: The psychological contract as a framework for understanding career management, organizational commitment and work behavior. Journal of Organizational Behavior, 26, 821-838.

Sturges, J., Guest, D., Conway, N., \& Davey, K.M. (2002). A longitudinal study of the relationship between career management and organizational commitment among graduates in the first ten years at work. Journal of Organizational Behavior, 23, 731-748.

Sturges, J., Guest, D., \& Mackenzie Davey, K. (2000). Who is in charge? graduates attitudes to and experiences of career management and their relationship with organizational commitment. European. Journal of Work and Organizational Psychology, 9(3), 351-370.

Sullivan, S. E. (1999). The changing nature of careers: A review and research agenda. Journal of Management, 25(3), 457-484.
Yu, B.B., \& Egri, C.P. (2005). Human resource management practices and affective organizational commitment: A comparison of Chinese employees in a state-owned enterprise and a joint venture. Asia Pacific Journal of Human Resources, 43(3), 332-360. 